\title{
Research on the Flow Characteristics of Sudden-Reduction Oil Tube
}

\author{
Zhibin Zhang ${ }^{*}, 1$, Chunxi Lin ${ }^{1}$, Weiqiang $\mathrm{Ye}^{1}$, An Wei ${ }^{1}$, Leming Xiao ${ }^{1}$ and Wanzheng $\mathrm{Ai}^{2}$ \\ ${ }^{1}$ Guangzhou Maritime Institute, Guangzhou 510725, China \\ ${ }^{2}$ Zhejiang Ocean University, Zhoushan 316021, China
}

\begin{abstract}
The backflow region length in sudden-reduction oil tube is not only closely associated with its energy loss, but is also closely related to the partition between orifice plate and plug. In this paper, the characteristics of backflow region length in sudden-reduction oil tube are researched. The results illustrated that backflow region length decreases with the increase in the contraction ratio. Moreover, when Reynolds number is more than 105, Reynolds number has little impact on backflow region length. Empirical expression about backflow region length in sudden-reduction oil tube is also discussed in this paper.
\end{abstract}

Keywords: Backflow region, Contraction ratio, Reynolds number, Simulations, Sudden-reduction.

\section{INTRODUCTION}

Sudden enlargement and sudden reduction flows have been applied widely in fluid measurement. In recent years, with the development of techniques, sudden enlargement and sudden reduction forms pipes were used to dissipate energy in tunnel [1]. As early as 1960's, a plug dissipater, as a kind of energy dissipater with sudden reduction and sudden enlargement forms, was used in the flood discharge tunnel of the Mica dam in Canada, and it gained energy dissipation ratio of over $50 \%$ [2]. In 2000, a three-stage sharp-edged orifice plate, similar to orifice plate in energy dissipation mechanism, was applied in the Xiaolangdi Projects in China, and obtained the energy dissipation ratio of about $44 \%$ [35].

The flow through sudden-reduction oil tube is shown in Fig. (1). The backflow region was observed in the suddenreduction oil tube. Many researches on sudden reduction tube flow were conducted, but the interesting areas focused were the effects of the geometric parameters on energy loss coefficient [6-8]. Wang and Yue [9] presented an approximate method to calculate the local resistance coefficients of both sudden reduction and sudden enlargement by means of physical model experiments, and they $[8,9]$ deemed that that the energy losses of both sudden reduction flows and sudden enlargement flows increased with the decrease in the contraction ratio $(d / D$ is the contraction ratio, shown in Fig. (1)). As a matter of fact, the backflow region length defined $L_{b}$ in Fig. (1), is not only the original region of the energy dissipation $[10,11]$, but also is the crucial factor which affects the distinguishing aspect between plug and orifice plate, so it is important to study the characteristics of sudden reduction tube flow. The aims of the present work, therefore, were to investigate the effects of the geometric and hydraulic parameters on the backflow

*Address correspondence to this author at the Guangzhou Maritime Institute, Hongshan San Road, Huangpu, Guangzhoux, Postcard: 510725, China; Tel: 18922772102; E-mail: zzb0206@163.com region length and to present an empirical expression of the sudden reduction oil tube's backflow region length by means of the numerical simulations.

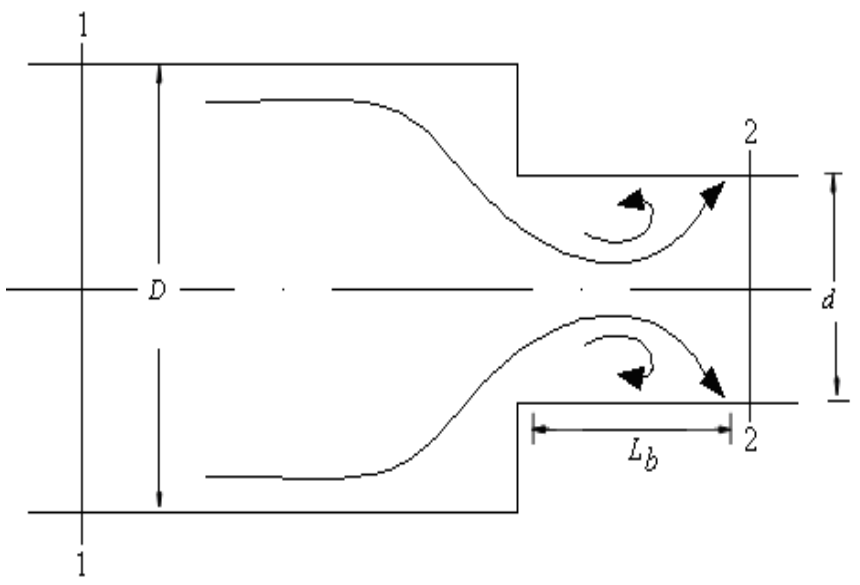

Fig. (1). Sudden reduction tube oil flow.

\section{NUMERICAL SIMULATIONS MODEL}

The $\mathrm{RNG} \mathrm{k} \sim \varepsilon$ model was used to calculate the hydraulic parameters of the oil flow through sudden enlargement tube and sudden reduction tube, due to their suitability for simulation. For steady and incompressible flows, the governing equations of this model can be written as:

Continuity equation $[12,13]$ :

$\frac{\partial u_{i}}{\partial x_{i}}=0 \quad i=1,2$

Momentum equation:

$u_{j} \frac{\partial u_{i}}{\partial x_{j}}=-\frac{1}{\rho} \frac{\partial p}{\partial x_{i}}+\frac{\partial}{\partial x_{j}}\left[\left(v+v_{t}\right)\left(\frac{\partial u_{i}}{\partial x_{j}}+\frac{\partial u_{j}}{\partial x_{i}}\right)\right] i=1,2$

k-equation:

2015 Bentham Open 
$u_{i} \frac{\partial k}{\partial x_{i}}=\frac{\partial}{\partial x_{j}}\left[\alpha_{k}\left(v+v_{t}\right) \frac{\partial k}{\partial x_{j}}\right]+\frac{1}{\rho} G_{k}-\varepsilon i=1,2$

$\varepsilon$-equation:

$u_{i} \frac{\partial \varepsilon}{\partial x_{i}}=\frac{\partial}{\partial x_{j}}\left[\alpha_{\varepsilon}\left(v+v_{t}\right) \frac{\partial \varepsilon}{\partial x_{j}}\right]+\frac{1}{\rho} C_{1}^{*} G_{k} \frac{\varepsilon}{k}-C_{2} \frac{\varepsilon^{2}}{k} i=1,2$

Where $\mathrm{xi}(=\mathrm{x}, \mathrm{y})$ are the coordinates in longitudinal and transverse directions, respectively; $u i=(=u x, u y)$ are the velocity components in $\mathrm{x}$ and $\mathrm{y}$ directions, respectively; $\rho$ is the density of oil; $p$ is the pressure; $v$ is the kinematic viscosity; $v t$ is the eddy viscosity and can be given by $v t=$ $\mathrm{C} \mu(\mathrm{k} 2 / \varepsilon)$, in which $\mathrm{k}$ is the turbulence kinetic energy, and $\varepsilon$ is the dissipation rate of $\mathrm{k}$ and $\mathrm{C} \mu=0.085$. The other parameters are:

$$
\begin{aligned}
& C_{1}^{*}=C_{1}-\frac{\eta\left(1-\eta / \eta_{0}\right)}{1+\lambda \eta^{3}}, \eta=S k / \varepsilon, S=\frac{1}{2}\left(\frac{\partial u_{i}}{\partial x_{j}}+\frac{\partial u_{j}}{\partial x_{i}}\right), C_{1} \\
& =1.42, \eta_{o}=4.377, \lambda=0.012, G_{k}=\rho v_{t}\left(\frac{\partial u_{i}}{\partial x_{j}}+\frac{\partial u_{j}}{\partial x_{i}}\right) \frac{\partial u_{i}}{\partial x_{j}}, C_{2} \\
& =1.68 \text { and } \alpha_{k}=\alpha_{\varepsilon}=1.39 .
\end{aligned}
$$

The calculation boundary conditions are treated as follows. In the inflow boundary, the turbulent kinetic energy $k_{i n}$ and the turbulent dissipation rate $\varepsilon_{i n}$ can be defined as respectively $[12,13]$ :

$k_{\text {in }}=0.0144 u_{\text {in }}^{2} \varepsilon_{\text {in }}=k_{\text {in }}^{1.5} /(0.25 D)$

Where $u_{\text {in }}$ is the average velocity in the inflow boundary. In the outflow boundary, the oil flow is considered as fully developed. The wall boundary is controlled by wall functions. Symmetric boundary condition is adopted, that is, the radial velocity on symmetry axis must be zero.

Because the sudden reduction tube has axial symmetry characteristics, three dimensional numerical simulations of oil flows can be simplified as two dimensional numerical simulations of tube flows. The 3-D coordinate axis of sudden reduction tube is shown in Fig. (2). In this paper, flows' characteristics of plane $X Z$ were studied. The characteristics of oil flows in plane $X Z$ can represent the whole tube oil flows characteristics.

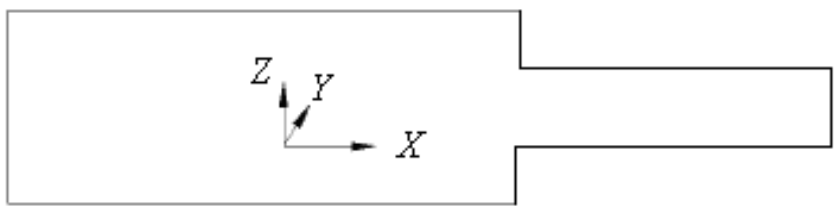

Fig. (2). 3-D coordinate axis of sudden reduction oil tube.

\section{ANALYSES}

\subsection{Numerical Simulation Results}

The simulation results are shown in Tables $\mathbf{1}$ and $\mathbf{2}$ respectively. $\mathrm{lb}$ in Tables $\mathbf{1}$ and $\mathbf{2}$ is the relative backflow region length. Re in Tables $\mathbf{1}$ and $\mathbf{2}$ is the Reynolds number.
Table 1. Variations of $l_{b}$ with $\operatorname{Re}(d / D=0.50)$.

\begin{tabular}{|c|c|c|c|c|c|}
\hline $\boldsymbol{R e}\left(\times \mathbf{1 0}^{\mathbf{5}}\right)$ & 0.9 & 1.8 & 9.2 & 18.4 & 27.6 \\
\hline $\boldsymbol{l}_{\boldsymbol{b}}$ & 0.60 & 0.61 & 0.61 & 0.61 & 0.61 \\
\hline
\end{tabular}

Table 2. Variations of $l_{b}$ with $d / D\left(R e=1.8 \times 10^{5}\right)$.

\begin{tabular}{|c|c|c|c|c|c|}
\hline $\mathbf{d} / \mathbf{D}$ & 0.4 & 0.5 & 0.6 & 0.6 & 0.8 \\
\hline $\boldsymbol{l}_{\boldsymbol{b}}$ & 0.61 & 0.57 & 0.53 & 0.50 & 0.48 \\
\hline
\end{tabular}

\section{DISCUSSION}

It could be observed from Table $\mathbf{1}$ that the relative backflow region lengths $l_{b}$ hardly changed with Reynolds number $R e$ when Reynolds number $R e$ was more than $10^{5}$. They changed from 0.6 to 0.61 respectively with regard to the changes of Reynolds number $R e$ from $9.00 \times 10^{4}$ to $2.76 \times 10^{6}$ under the condition of $d / D$ being 0.50 . Therefore it can be concluded that the effects of Reynolds number Re could be neglected on the relative backflow region length $l_{b}$ when Reynolds number $R e$ is more than $10^{5}$. Table 2 shows the effects of contraction ratio $d / D$ on the relative backflow region length $l_{b}$. It can be concluded that the larger the contraction ratio $d / D$, the smaller the relative backflow region length $l_{b}$. The empirical expression, by means of the numerical simulation results from Fig. (2), could be obtained as:

$l_{b}=0.36(d / D)^{2}-0.76(d / D)+0.86$

This expression is valid for $d / D=0.4-0.8, R e>10^{5}$.

\section{CONCLUSION}

For sudden reduction tube oil flows, its relative backflow region length $l_{b}$ decreased with increase in the contraction ratio $d / D$. When Reynolds number Re was more than $10^{5}$, Reynolds number $R e$ had little effects on relative backflow region length $l_{b}$. By fitting relating curves, relative backflow region length $l_{b}$ and empirical expressions of sudden reduction tube oil flow were obtained in this paper.

\section{CONFLICT OF INTEREST}

The authors confirm that this article content has no conflict of interest.

\section{ACKNOWLEDGEMENTS}

Declared none.

\section{REFERENCES}

[1] J.P. Zhou, Z.Y. Yang, and G.F. Chen, "Status and challenges of high dam in China", J. Hydraul. Eng., vol. 37 no. 12, pp. 14331438, 2006. (in Chinese)

[2] S. O. Russell, and J. W. Ball, "Sudden-enlargement energy dissipator for Mica dam", J Hydr. Eng. Div-Asce., vol. 93, no. 4, pp. 41-56, 1967.

[3] Z.Y. Li, X. Chen, and M.F. Chen, "Study on hydraulic problems of spillway tunnels with orifices reformed from diversion tunnel", $J$. Hydraul. Eng., no. 2, pp. 1-10, 1997 (in Chinese) 
[4] J.H. Wu, and W.Z. Ai. "Flows through energy dissipaters with sudden reduction and sudden enlargement forms", J Hydrodynam B., vol. 22, no. 3, pp. 234-345, 2010.

[5] H.G. Ni, "Estimation of incipient cavitation number of spillway tunnel with orifice", J Hydrodynam A., vol. 10, no. 4, pp. 419-429, 1995. (in Chinese)

[6] W.Z. Ai, and T.M. Ding, "Orifice plate cavitations mechanism and its influencing factors”, J. Water Sci., vol. 3, no. 3, pp. 321-330, 2010.

[7] J.H. Wu, W.Z. Ai, and Q. Zhou. "Head loss coefficient of orifice plate energy dissipaters". J. Hydraul. Res., vol. 48. no. 4, pp. 526530,2010

[8] Z. Tian, W.L. Xu, W. Wang, and S.J. Liu, "Hydraulic characteristics of plug energy dissipater in flood discharge tunnel," $J$. Hydrodyn. Ser. B., vol. 21, no. 6, pp. 799-806, 2009.
[9] D.C. Wang, and P.J. Yue. "An experimental study on energy dissipation of orifice plate in the tube", J. Hydrodyn. Ser. A., vol. 2, no. 3, pp. 41-50, 1987. (in Chinese).

[10] J.M. Zhang, W.L. Xu, S.J. Liu, W. Wang, "Numerical simulation of turbulent flow in throat type energy dissipators," J. Hydrau. Eng., vol. 12, pp. 27-39, 2004. (in Chinese).

[11] J.X. Qu, Y.Q. Yang, J.M. Zhang, W.L. Xu, "Numerical simulation of cavitation on orifice energy-dissipator," J. Sichuan Univ. (Eng. Sci. Ed.), vol. 33, no. 3, pp. 30-36, 2001. (in Chinese).

[12] J.X. Qu, W.L. Xu, Y.Q. Yang, "Numerical simulation of flow through orifice energy dissipaters in XIAOLANGDI flood discharge tunnel", J. Hydrodyna., Ser. B, vol. 3, pp.41-46, 2000.

[13] Q.F. Xia, H.G. Ni, "Numerical simulation of plug energy dissipater", J. Hydra. Eng., vol. 8, pp. 37-47, 2003. (in Chinese).

(c) Zhang et al.; Licensee Bentham Open.

This is an open access article licensed under the terms of the Creative Commons Attribution Non-Commercial License (http://creativecommons.org/licenses/by-nc/4.0/) which permits unrestricted, non-commercial use, distribution and reproduction in any medium, provided the work is properly cited. 